\title{
Protective Techniques Followed by Nurses to Prevent X-ray Exposure During Fluoroscopic Guided Surgeries
}

\author{
K. H. G. N. Dilusha, H. A. P. Tharanga, K. P. N. S. De Silva \\ and B. S. S. De Silva ${ }^{1}$ \\ ${ }^{1}$ Department of Health Sciences, The Open University of Sri Lanka
}

\begin{abstract}
Fluoroscopy is a type of medical imaging that shows a continuous $\mathrm{X}$-ray (ionizing radiation) image on a monitor. Fluoroscopic guided surgeries are increasing all over the world. However, the danger of X-ray exposure may be an issue for health care workers including nurses. X-ray can cause both somatic and genetic damages such as squamous cell carcinoma of hands, leukemia, thyroid cancers, stomach cancers, and birth defects. The aim of this study was to examine protective techniques followed by nurses to prevent X-ray exposure during fluoroscopic guided surgeries. This quantitative descriptive study was conducted in three main hospitals in Sri Lanka; namely National Hospital of Sri Lanka (NHSL), Colombo South Teaching Hospital (CSTH), and Sri Jayewardenepura General Hospital (SJGH). The convenience sampling method was utilized to recruit 100 nurses who are working in fluoroscopic theatres of these hospitals. A self-administered questionnaire was used as a tool for data collection. The study revealed a sound knowledge regarding X-ray protective techniques and poor knowledge regarding international standard protective techniques to protect themselves from X-ray exposure among nurses. However, attitudes are satisfactory. Existing practices of X-ray protective techniques are poor. Insufficient equipment, lack of knowledge and modern technology, poor training facilities were identified as barriers to use X-ray protective techniques. Health authorities of Sri Lanka should
\end{abstract}

${ }^{1}$ Correspondence should be addressed to B. S. S. De Silva, Department of Health Sciences, The Open University of Sri Lanka (Email: bssil@ou.ac.lk) 
accept the importance of X-ray protection, and should provide appropriate training, policies and equipment. Overall changes are also needed in hospital administration to facilitate adequate educational sessions, protective devices and technology on X-ray protection for health care workers including nurses.

Keywords: Fluoroscopy, Nurses, Protective techniques, X-ray

\section{Introduction}

Fluoroscopic guided surgery has increased in Sri Lanka. United States Food and Drug Administration (2014) defined fluoroscopy as a type of medical imaging that shows a continuous X-ray movie on a monitor. Therefore, the movement of a body part or an instrument or $\mathrm{X}$-ray dye can be seen in detail throughout the fluoroscopic guided surgery. Fluoroscopy is a source of ionizing radiation (X-ray) and therefore, the operating theatre personnel including theatre nurses are exposed to X-ray frequently. It is a potential health hazard with continued exposure during fluoroscopic guided surgery (Mariscalco et al., 2011).

The University of Chicago Medicine (2014) highlighted that fluoroscopy makes interventions less invasive. Further, they pointed out that the advantages of fluoroscopic guided surgery are less postoperative pain and discomfort, a shorter hospital stay and quicker return to normal activities, smaller incisions which means smaller and less noticeable scars, leading to less tissue damage and quicker recovery and a higher accuracy rate for most procedures. Hayashi (2008) stated that minimally invasive procedures have many benefits for the patient, but the use of fluoroscopy is problematic for operating room personnel concerned about X-ray exposure. The patient's exposure is limited to one or few operations but the surgeon and the operating room personnel are repeatedly exposed to X-ray during multiple procedures. This exposure can be a cause for changes of body cells and potentially increased risk of cancer. Even relatively small doses should be considered as dangerous over longterm (Patrick \& McCormick, 2008).

World Health Organization (2011) has classified X-ray as a carcinogen. Risks of excess X-ray exposure are not insignificant, potentially leading to a variety of health issues such as birth defects, cataracts, hair loss and the development of cancers. It is easy to become complacent about the dangers of X-ray as it is invisible and odorless, and therefore health care workers are often caught up in 
performing procedures. As a result, health care workers and patients may be exposed to a higher level of X-ray (Kiah \& Stueve, 2012).

There were many studies highlighting the risk of X-ray exposure to the operating surgeons as well as assistants and nursing staff in other countries (Flor \& Gelbcke, 2013; Linet et al., 2010; Nelson et al., 2014; Vano et al., 2010; Yunus et al., 2014 \& Yurt et al., 2014). Among these, most studies were done in developed countries than developing countries related to radiation safety. Many studies found that the knowledge regarding using protective techniques to prevent radiation exposure among nurses was not satisfactory all around the world (Linet et al., 2010; Mariscalco et al., 2011 \& Yurt et al., 2014). Osman et al. (2013) emphasized that well training and knowledge about hazards are initial steps needed to reduce radiation risk.

International standard protective techniques are methods using a set of mandatory requirements, based on the knowledge of biological effects of radiation and on principles for protection from undesirable effects (Wrixon, 2008). Sign on the door, wearing lead lined gloves, using eye wear, thyroid guards, lead aprons, steel-toed shoes, standing behind a lead lined shield; staying away from the X-ray beam at least six feet and using hand free techniques are considered as international standard protective techniques.

Kesavachandran et al. (2012) stated that the international commission on radiological protection has established the standards for radiation protection. Further, they pointed out that most of the nurses do not practice X-ray protective techniques properly. Health care workers involved in X-ray should be monitored monthly or quarterly by using dosimeters that help to quantify the X-ray exposure dosage and it should not be allowed to exceed the annual permissible limits (Wrixon, 2008). According to Banfield (2012), a unique problem in the operating room is protective devices that need to be worn under sterile clothing. The author further stated that the protective devices are heavy, uncomfortable and not welcomed by most operating room personals. There was some evidence highlighting the differences between using and not using protective techniques and garments. Bahari et al., (2006) recommended the adherence to the basic principle of 'As Low as Reasonably Achievable (ALARA)' (making every reasonable effort) in any fluoroscopic assisted procedures. Therefore, routinely monitoring of X-ray exposure by using dosimeters is essential in preventing radiation related diseases. Soares, Pereira and Flor (2011) in Brazil, found that ALARA principles such as distance from the X-ray source, time 
of X-ray exposure and shielding, decrease the dose exposure for occupationally X-ray exposed individuals.

In Sri Lanka, there were no published studies related to X-ray exposure and protective techniques used by health care workers including nurses. Due to the minimal literature, the Sri Lankan situation regarding the X-ray exposure in fluoroscopic guided surgery is not known. Yet, radiation protection is one of the main issues for occupational health of nurses who are engaged with fluoroscopic guided surgeries in Sri Lanka. Therefore, it is necessary to examine the protective techniques followed by nurses to minimize $\mathrm{X}$-ray exposure during fluoroscopic guided surgery.

The main purpose of the study was to inquire in to the protective techniques followed by Sri Lankan nurses to prevent X-ray exposure during fluoroscopic guided surgery. The other specific aims of this study were to identify knowledge and attitudes among nurses to prevent X-ray exposure during fluoroscopic guided surgery, existing practices and barriers in following protective techniques to prevent $\mathrm{X}$-ray exposure during fluoroscopic guided surgery.

Findings of this study will help to assess the awareness of nurses regarding protection from X-ray during fluoroscopic guided surgery. It will contribute to the development of the nursing practice by providing appropriate X-ray related education for nurses. It will also help to identify the importance of facilitating adequate protective devices, introduce guidelines for protection from X-ray and improve awareness of X-ray protection among Sri Lankan nurses. Finally, this study will help further studies related to X-ray protection among health care workers including nurses.

\section{Methodology}

A quantitative descriptive design was utilized in this study. It is best suited for the study as it helps to describe what exists and uncover new facts and meaning (Polit \& Hungler, 1983; Martyn, 2008).

\section{Sample and Setting}

The participants of this study were nurses who work in the operating theatres in three main hospitals in Sri Lanka; which were National Hospital of Sri Lanka (NHSL), Colombo South Teaching Hospital (CSTH), and Sri Jayewardenepura General Hospital (SJGH). 
There were 80 fluoroscopic guided surgeries done in NHSL, 45 fluoroscopic guided surgeries in CSTH and 40 in SJGH per month in 2014.

One hundred nurses who work in the operating theatres and who are involved with fluoroscopic guided surgeries in the selected three main hospitals were recruited as a convenience sample. Both male and female nurses who had at least 02 years of working experience with fluoroscopic guided surgery were considered as inclusion criteria for the selection. Further, the sample was under the different age limits and all are registered nurses in Medical or Nursing Council in Sri Lanka. The ethical approval was granted by the ethical review committees of NHSL, CSTH and SJGH and permission was taken from the Directors of these hospitals to conduct this study. After information sheets were distributed, informed consent was taken from the participants of the study. No ethical issues were encountered throughout the study.

\section{Data Collection}

The research tool was a self-administered questionnaire that was validated by using reviewed literature and finalized with expert opinion (Denzin \& Lincoln, 2005). As a pilot study, the questionnaire was distributed among ten participants who did not participate in the study (Shuttleworth, 2010). It was focused on participants' demographic data; nurses' knowledge regarding the manner in which parts of the body are affected, and international standard safe techniques and attitudes towards X-ray safety; the existing practice of safety techniques to prevent X-ray and barriers to practice safety techniques. The pre tested and validated questionnaire was distributed among the selected group for data collection during $15^{\text {th }}$ November to $10^{\text {th }}$ December in 2014. Participants were fully informed regarding the purpose of the study and the methods to ensure ethical aspects of participants' involvement. Completed questionnaires were collected by keeping a separate file in the corner of the nurses' station to protect the confidentiality of the participants (Whelan, 2007).

\section{Data Analysis}

Data was analyzed by using Statistical Package for the Social Sciences (SPSS) 16.0 version with the purpose of drawing 
conclusions from the information. Microsoft Excel Package was also used for data management.

\section{Results}

The general demographics of the participants for gender showed that $95 \%$ were female while $5 \%$ were male nurses. Forty one from NHSL, 30 from CSTH and 29 from SJGH were represented in the sample. In terms of academic qualifications, $60 \%$ of the respondents were diploma holders whereas $28 \%$ were undergraduates and $12 \%$ were B.Sc. nursing graduates. Only $7 \%$ of participants had more than 20 years of working experiences. There were $22 \%$ of participants had 11-20 years working experiences, $12 \%$ had 6-10 years of working experiences, and $42 \%$ had 3-5 years of working experience with fluoroscopic guided surgery.

\section{Nurses' Knowledge regarding Protective Techniques}

Surprisingly 99\% of the nurses aware that the exposure of X-ray will damage the thyroid gland and more than $95 \%$ of nurses accepted that brain and genital organs could be damaged from X-ray. More than $80 \%$ of nurses mentioned that the eye, thoracic and abdominal organs can also be damaged due to X-ray. More than $60 \%$ of the nurses have reported that there is no harm to the hair and teeth due to X-ray exposure (Figure 1).

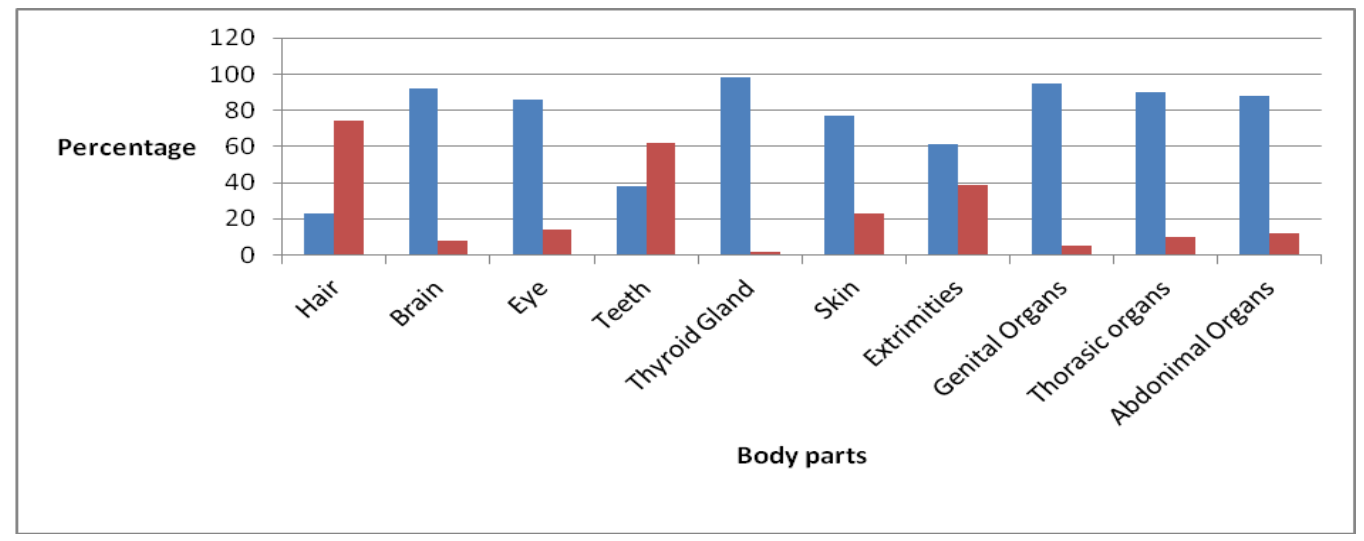

Damage to body parts from X-ray

No damage to body parts from X-ray

Figure 1. Nurses' knowledge regarding damage to body parts from $\mathrm{X}$-ray 
Additionally, 99\% of the nurses were unaware of ALARA principles (time, distance, shielding), but $100 \%$ of participants accepted the importance of wearing led aprons and 99\% accepted wearing thyroid guards as international standards. Nearly $80 \%$ of the nurses recognized the sign on the door about the risk of radiation, wearing X-ray protective eye wear, and standing behind a lead lined shield as international standard protective techniques. It seems that around $60 \%$ of the nurses wear lead lined gloves and use hand free technique as international protective techniques to protect hands from X-ray. Around $65 \%$ of them recognized the importance of using dosimeters to indicate dosage of personal X-ray exposure. Further $58 \%$ of nurses identified that to reduce X-ray exposure they should stay away from the X-ray beam (at least six feet) as an international standard protective technique. In contrast, $63 \%$ of the nurses did not believe wearing steel-toed shoes as an international standard protective technique (Figure 2).

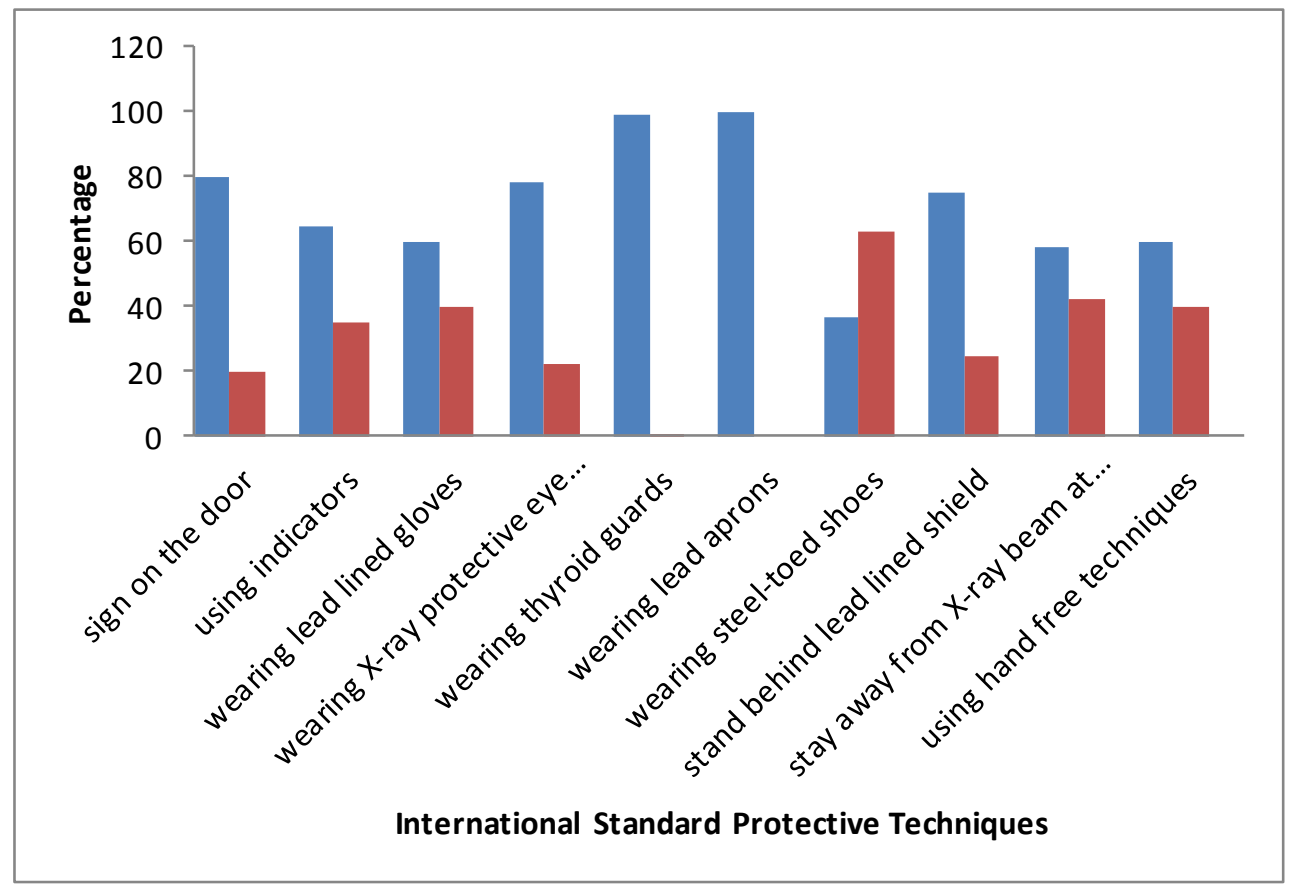

Accept as international standard protective technique Not accept as international standard protective technique

Figure 2. Nurses' knowledge of international standard protective techniques for X-ray protection 


\section{Nurses' Attitudes towards X-ray Protection}

Eighty seven percent of nurses believed that the assisting nurse must wear protective lead shields, while $75 \%$ of the nurses believed that the circulating nurse must also wear protective lead shields. It was found that $96 \%$ of the nurses agree to wear protective lead shields even their family is completed (having enough children). In contrast, $44 \%$ of nurses pointed out that they have inadequate knowledge regarding X-ray protection. There was $92 \%$ of the study sample agreed that their knowledge regarding X-ray protection must be updated (Table 1).

Table 1. Nurses' attitudes towards X-ray protection

\begin{tabular}{|c|c|c|c|}
\hline Statement & Disagree & Neutral & Agree \\
\hline $\begin{array}{l}\text { 1. All the persons of the health care team wear } \\
\text { protective lead shields during fluoroscopic } \\
\text { surgery. }\end{array}$ & $2 \%$ & $14 \%$ & $84 \%$ \\
\hline $\begin{array}{l}\text { 2. When person present without lead apron and } \\
\text { a thyroid shield in the theatre X-ray } \\
\text { technician, stop X-ray screening. }\end{array}$ & $3 \%$ & $8 \%$ & $89 \%$ \\
\hline $\begin{array}{l}\text { 3. Persons enter the theatre without protective } \\
\text { Wearing when using } \mathrm{x} \text {-ray. }\end{array}$ & $4 \%$ & $4 \%$ & $82 \%$ \\
\hline $\begin{array}{l}\text { 4. When seeing X-ray screening by X-ray } \\
\text { technician unnecessarily without surgeons' } \\
\text { order, tell him to stop screening }\end{array}$ & $3 \%$ & $7 \%$ & $90 \%$ \\
\hline $\begin{array}{l}\text { 5. Wearing protective lead shields by assisting } \\
\text { nurse is important during fluoroscopic } \\
\text { surgery }\end{array}$ & $3 \%$ & $10 \%$ & $87 \%$ \\
\hline $\begin{array}{l}\text { 6. Wearing protective lead shields by circulating } \\
\text { nurse is important during fluoroscopic } \\
\text { surgery }\end{array}$ & $7 \%$ & $18 \%$ & $75 \%$ \\
\hline $\begin{array}{l}\text { 7. Wearing protective lead shields is necessary } \\
\text { when my family is completed (having enough } \\
\text { children). }\end{array}$ & $1 \%$ & $3 \%$ & $96 \%$ \\
\hline $\begin{array}{l}\text { 8. I have adequate knowledge regarding X-ray } \\
\text { protection }\end{array}$ & $44 \%$ & $27 \%$ & $29 \%$ \\
\hline $\begin{array}{l}\text { 9. My knowledge regarding X-ray protection } \\
\text { must be updated }\end{array}$ & $4 \%$ & $4 \%$ & $92 \%$ \\
\hline
\end{tabular}


Existing Practices of Nurses in Protective Techniques with Fluoroscopic Guided Surgeries

The results of the study showed that $99 \%$ of nurses wearing thyroid shield and lead apron as current practice of protective techniques. In contrast $99 \%$ of them did not use dosimeters, 94\% not used steel toed shoes, $89 \%$ refused to wear lead gloves and $82 \%$ were not used red light or alarm on the door as current use safe techniques. Nearly $70 \%$ of nurses did not follow the standard of 'at least six feet away from X-ray beam' and $58 \%$ of them did not practice hand free technique from direct $\mathrm{X}$-ray beam to reduce X-ray exposure. Furthermore about $50 \%$ of the sample used protective goggles while $50 \%$ of them did not follow the standard of 'behind lead lined shield' (Figure 3). The overall sample (100\%) was accepted that they did not have opportunity to engage in training programs or sessions on $\mathrm{X}$ ray protection.

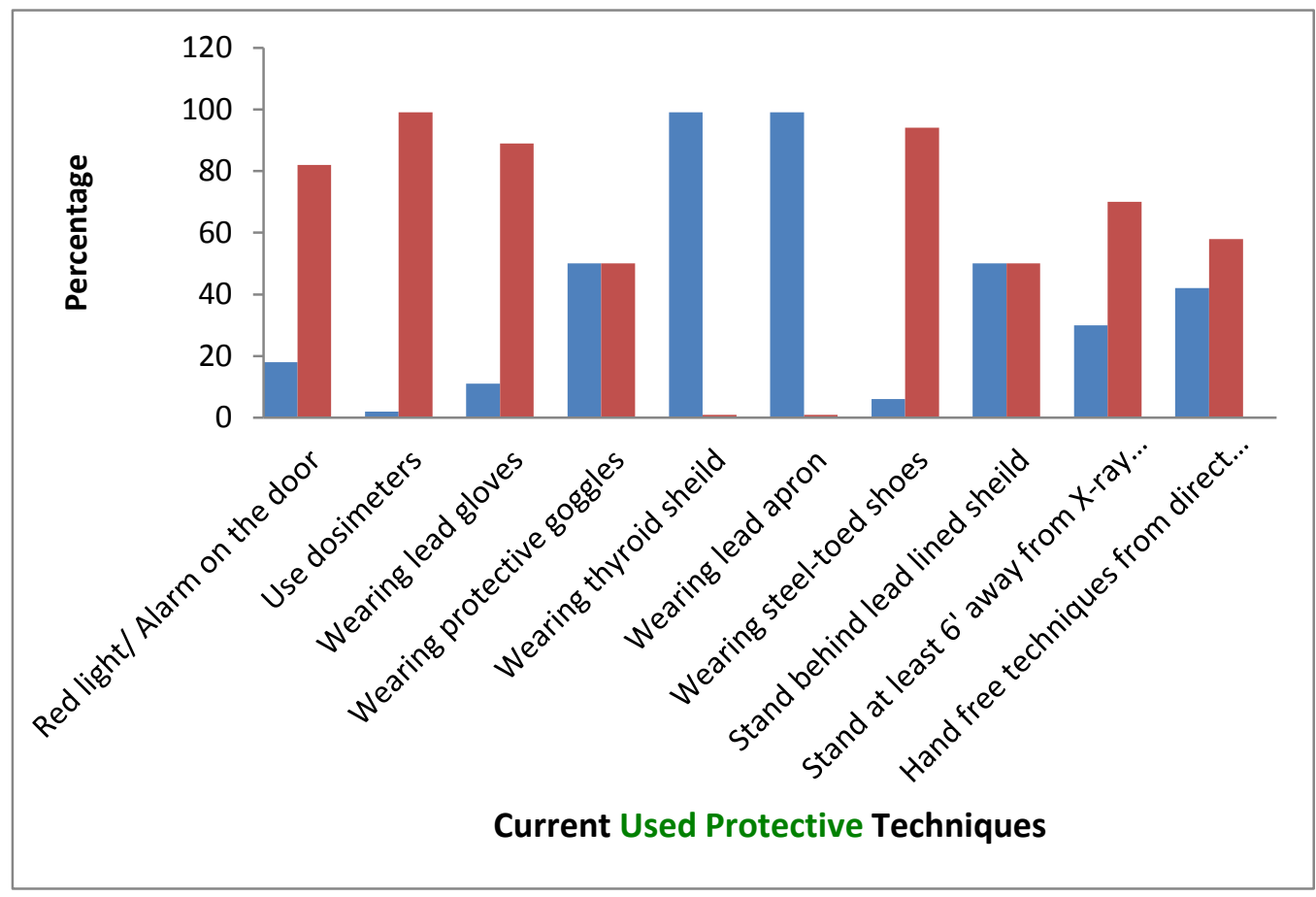

Practice as safe technique

$\square$ Do not practice as safe technique

Figure 3. Existing practices of $\mathrm{X}$-ray protective techniques among nurses 


\section{Barriers to Practice Protective Techniques to Prevent X-ray Exposure}

There were barriers to practice protective techniques. According to the study results, $72 \%$ of nurses identified the heavy weight of the lead apron as a barrier to practice safe techniques. Additionally, $40 \%$ of nurses did not like to wear common aprons. Further, 54\% of nurses recognized the shortage of lead aprons and other shields as barriers to practice protective techniques to prevent X-ray exposure during fluoroscopic guided surgery.

\section{Discussion}

This study found out that most of the nurses have satisfactory knowledge about damage of the brain, thyroid gland, genital organs, thoracic organs, abdominal organs, eye and skin due to X-ray exposure. However, they did not have adequate knowledge about the damage of extremities (hands), hair and teeth from X-ray. Based on the result, the researchers would like to highlight that nurses did not have knowledge about ALARA principles which help to minimize personal X-ray exposure same as in Turkey (Yurt et al., 2014). Nurses' knowledge about radiation safety and X-ray protection in Korea is also poor (Park et al., 2012). Similarly nurses did not have adequate knowledge regarding the effects of X-ray and international standard protective techniques. They do not have a basic training program about $\mathrm{X}$-ray protection and it may be one of the reasons for this inadequate knowledge.

The nurses accepted wearing the lead apron as an international standard protective technique. Further, most of them identified the red alarm or sign on the door, wearing X-ray barrier goggles, thyroid shields and standing behind lead lined shields as international standard safe techniques against X-ray. Furthermore, they had knowledge regarding using dosimeters to indicate the dosage of personal X-ray exposure. However, the majority of the sample had inadequate knowledge related to the international standard protective techniques. They did not know hand free technique and distance principle. This situation is the same in Kuwait and they found that nurses who worked in the radiology department had inadequate knowledge of X-ray protection measures and less knowledgeable about the risks of radiation (Alotaibi \& Saeed, 2006). This lack of knowledge in some areas means that the nurses are 
unable to effectively protect themselves, the health team as well as their patients from unnecessary X-ray exposure.

According to the study, most of the nurses had positive attitudes towards using X-ray protective techniques. Almost all of the nurses had a positive attitude related to the concern of protection of themselves as well as their team members. Additionally a vast majority of the nurses wanted to update their knowledge and develop attitudes about X-ray protection. It is similar to the findings from the study done in Kuwait and they pointed out that nurses were concerned about radiation and would like to learn more about health risks associated with radiation (Alotaibi \& Saeed, 2006).

Although nurses had positive attitudes towards X-ray protective techniques, there were no standard and acceptable education programmes on radiation safety related to X-ray protection. Situation of Turkey is also the same as in Sri Lanka (Yurt et al., 2014).

In Sri Lanka there was no evidence of using dosimeters to measure personal exposure dosage of X-ray radiation during fluoroscopic guided surgery. Almost all the nurses of the study sample were using lead aprons and thyroid shields as their basic X-ray protective techniques. Some of them used protective goggles. They were not using any other protective technique such as wearing steel toed shoes and led lined gloves. There were no warning red lights or alarms at most of the theatres. Half of the sample did not follow protective techniques for safety of extremities. Especially, they were not aware of hand protection from direct X-ray beam. They did not use distance method which is standing at least six feet away from direct X-ray beam to prevent unnecessary X-ray exposure. In contrast, nurses in Korea used protective garments, safe distance and less exposure time as protective measures which are commonly used and therefore, they were able to limit the exposure from the primary and scatter radiation source (Jung et al., 2013). The major reasons for not using $\mathrm{X}$ - ray protective techniques in this study may be shortage of protective garments, lack of knowledge and lack of training about radiation protection. Therefore, the practice of safe techniques to prevent X-ray exposure is significantly poor among nurses.

According to the findings, there were significant barriers for using radiation protective techniques in health care setting in Sri Lanka. Most of the nurses identified that the heavy weight of the lead apron as a main barrier to using protective garments. More than half of the 
nurses noted the shortage of protective devices such as lead lined aprons, goggles and other shields. Half of them disliked wearing common aprons. There was a noticeable shortage of protective devices in above research setting. However, in United States of America the situation is different and they routinely monitor personal exposure of ionizing radiation dosage by using dosimeters (Bahari et al., 2006). Unfortunately fluoroscopic theatres of NHSL, SJGH and CSTH in Sri Lanka dosimeters were not available. The reason for this may be that Sri Lanka is a developing country. As a developing country, insufficient equipment, poor use of modern technology, lack of training and lack of knowledge could be the barriers for radiation protection.

\section{Conclusion}

Huge advances in diagnostic imaging capabilities in the past two decades have made radiology as a crucial part to guide many surgeries. Safety from X-ray is a critical part for operating room personal often ignored in Sri Lanka.

Nurses have sound knowledge regarding X-ray protection. However, they did not have an adequate knowledge regarding ALARA principles and had poor knowledge regarding parts of the body that can be damaged by X-ray. A majority of nurses had inadequate knowledge related to international standard protective techniques to protect themselves from X-ray exposure. Further, they did not have adequate knowledge regarding effects of $\mathrm{X}$-ray as they did not have any basic training programs about X-ray protection. However, nurses' attitudes regarding X-ray protection among nurses are satisfactory. They had positive attitudes towards X-ray protective techniques. Most of the sample had recognized that they need to update their knowledge about X-ray protection.

According to the study, practice of safe techniques to prevent X-ray exposure is significantly poor among nurses. They only use lead aprons and thyroid shields as their basic technique for X-ray protection. Most of them do not follow protective techniques for safety of extremities (hands). They did not follow standing outside the path of the primary X-ray beam or secondary scattered X-ray from patient and as far as away from it as possible and maintaining safe distance which were important protective techniques. There was no evidence of using dosimeters to monitor radiation exposure among fluoroscopic theatres. 
Sri Lanka as a developing country, insufficient protective garments and equipment, and poor use of modern technology, lack of training and lack of knowledge could be the barriers in using protective techniques to prevent X-ray exposure.

\section{Recommendations}

It is recommended that the nurses' knowledge on X-ray be enhanced which includes basic education of radiation protection for nursing diploma curriculum through the Ministry of Health. The nurses should have a basic training regarding X-ray protection, before they are appointed to work at theatres with fluoroscopic guided surgery. Nurses already working with fluoroscopic guided surgery should update their knowledge and develop good attitudes regarding protective techniques. The researchers would further recommend following ALARA principles, providing adequate amount of protective devices, and using personal dosimeters to measure personal X-ray exposure level to prevent harmful levels of X-ray exposure in Sri Lanka, which is of critical importance at present.

\section{References}

Alotaibi, M., \& Saeed, R. (2006). Radiology nurses' awareness of radiation. Journal of Radiology Nursing, 25 (1), 7-12.

Bahari, S., Morris, S., Broe, D., Taylor, C., Lenehan, B. \& McElwain, J. (2006). Radiation exposure of the hands and thyroid gland during percutaneous wiring of wrist and hand procedures. Actaorthopaedicabelgica, 72 (2), 194.

Banfield, C. M., (2012). Radiation Safety in the Operating Room. West industry Court Deer Park: Wolf X ray Cooperation. Available online at http: //www.wolfxray.com/images/Radiation\%20Safety\%20Ar ticle\%20Dr\%20Banfield.pdf

Denzin, N. K., \& Lincoln, Y. S. (2005). Introduction: The discipline and practice of qualitative research. In N. K. Denzin \& Y. S. Lincoln (Eds.), The Sage handbook of qualitative research (3 Ed., pp. 1-32). Thousand Oaks: Sage Publications. 
Flor, R. D. C., \& Gelbcke, F. L. (2013). Radiation protection and the attitude of nursing staff in a cardiac catherization laboratory.Texto\&Contexto-Enfermagem, 22 (2), 416-422.

Hayashi, A. (2008). Radaition Exposure in the OR: Is it safe.

American Academy of Orthopedic Surgeons, Illinois. Available online at:

http://www.aaos.org/news/aaosnow/dec08/clinical1.asp

Jung, C. H., Ryu, J. S., Baek, S. W., Oh, J. H., Woo, N. S., Kim, H. K., \& Kim, J. H. (2013).Radiation exposure of the hand and chest during $\mathrm{C}$-arm fluoroscopy-guided procedures. The Korean journal of pain, 26 (1), 51-56.

Kesavachandran, C. N., \& Haamann, F., \& Nienhans, A. (2012). Radiation exposure of eyes, thyroid gland and hands in orthopaedic staff: a systematic review. European Journal of Medical Research.Germany : License Biomed Central Ltd.

Kiah, C., \& Stueve, D. (2012).The Importance of Radiation Safety for Healthcare Workers as Well as Patients.Cath Lab Digest, 20(1). Available online at: http://www.cathlabdigest.com/articles/ImportanceRadiation-Safety-Healthcare-Workers-Well-Patients

Linet, M. S., Kim, K. P., Miller, D. L., Kleinerman, R. A., Simon, S. L., \& de Gonzalez, A. B. (2010). Historical review of occupational exposures and cancer risks in medical radiation workers. Radiation research, 174(6b), 793-808.

Mariscalco, M. W., Yamashita, T., Steinmetz, M. P., Krishnaney, A. A., Lieberman, I. H., \& Mroz, T. E. (2011). Radiation exposure to the surgeon during open lumbar micro discectomy and minimally invasive micro discectomy: a prospective, controlled trial. Spine, 36 (3), 255-260.

Martyn, S. (2008).Quantitative Research Design. Available online at: https://explorable.com/quantitative-research-design

Nelson, E. M., Monazzam, S. M., Kim, K. D., Seibert, J. A., \& Klineberg, E. O. (2014). Intraoperative fluoroscopy, portable $\mathrm{X}$-ray, and CT: patient and operating room personnel radiation exposure in spinal surgery. The Spine Journal, 14 (12), 2985-2991. 
Osman, H., Elzaki, A., Sherif, K., Sulieman, A. \& Hamid, H. O. (2013) Research Article Orthopedist's Hands Radiation Doses during Orthopedic Surgery Procedures. 1(5):369-371.

Park, P. E., Park, J. M., Kang, J. E., Cho, J. H., Cho, S. J., Kim, J. H., \& Kim, Y. C. (2012). Radiation safety and education in the applicants of the final test for the expert of pain medicine. The Korean journal of pain, 25 (1), 16-21.

Patrick, W. \& McCormick, M. D. (2008). Fluoroscopy :Reducting Radiation Exposure in the OR., AANS Neurosurgeon, 17 (1), 14-16.

Polit, D. F., \& Hungler, B. P. (1983). Nursing research: Principles and Methods (6th Ed.). Philadelphia, Lippincott.

Shuttleworth, M. (2010). Pilot study. Experiment-Resources.com. Available online at: https://explorable.com/pilot-study

Soares, F. A. P., Pereira, A. G., \& Flor, R. D. C. (2011). Use of radiation protection clothing for dose reduction absorbed: an integrative literature review. Radiology Brazilian, 44: 97-103.

The University of Chicago Medicine. (2014). Fluoroscopy p[rocedure. Available online at: http://uchospitals.uat.staywellsolutionsonline.com/condition s/heart/cardiac/92,P07662?PrinterFriendly=true

U.S. Food and Drug Administration.(2014). Fluoroscopy. Available online at: http://www.fda.gov/RadiationEmittingProducts/RadiationEmittingProductsandProcedures/ MedicalImaging/MedicalX-Rays/ucm115354.htm

Vano, E., Kleiman, N. J., Duran, A., Rehani, M. M., Echeverri, D., \& Cabrera, M. (2010). Radiationcataract risk in interventional cardiology personnel. Radiation research, 174 (4), 490-495.

Whelan, T. J. (2007). Anonymity and confidentiality: Do survey respondents know the difference. In Poster presented at the 30th annual meeting of the Society of Southeastern Social Psychologists, Durham, NC.

World Health Organization (2011). Radiation over exposure. Available online at: http://www.oncologypractice.com/co/journal/articles/08020 89.pdf 
Wrixon, A. D. (2008). New ICRP recommendations. Journal of Radiological Protection, 28 (2), 161.

Yunus, N. A., Abdullah, M. H. R. O., Said, M. A., \& Ch'ng, P. E. (2014, November). Assessment of radiation safety awareness among nuclear medicine nurses: a pilot study. In Journal of Physics: Conference Series (Vol. 546, No. 1, p. 012015). IOP Publishing.

Yurt, A., Çavuşoğlu, B., \& Günay, T. (2014). Evaluation of Awareness on Radiation Protection and Knowledge About Radiological Examinations in Healthcare Professionals Who Use Ionized Radiation at Work. Molecular imaging and radionuclide therapy, 23 (2), 48.

Received: 30-4-2015 Revised: 13-7-2015 Accepted: 22-7-2015 